Journal Article

\title{
Effect of arabinogalactan protein complex content on emulsification performance of gum arabic
}

Han, L., Hu, B., Ma, R., Gao, Z., Nishinari, K., Phillips, G.O., Yang, J., Fang, Y

This article is published by Elsevier and is subject to a 12 month embargo. The definitive version of this article is available at:

https://www.sciencedirect.com/science/article/pii/S0144861719308379

\section{Recommended citation:}

Han, L., Hu, B., Ma, R., Gao, Z., Nishinari, K., Phillips, G.O., Yang, J., Fang, Y (2019) 'Effect of arabinogalactan protein complex content on emulsification performance of gum arabic', Carbohydrate Polymers. Available online 09 Aug 2019. doi: 10.1016/i.carbpol.2019.115170 


\section{Journal Pre-proof}

Effect of arabinogalactan protein complex content on emulsification performance of gum arabic

Lingyu Han, Bing Hu, Ruixiang Ma, Zhiming Gao, Katsuyoshi

Nishinari, Glyn O. Phillips, Jixin Yang, Yapeng Fang

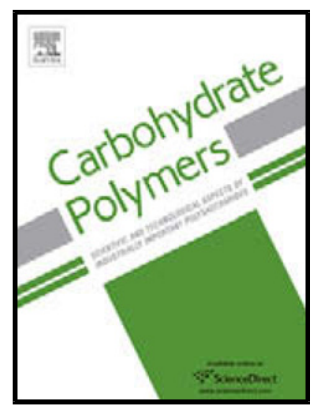

PII: $\quad$ S0144-8617(19)30837-9

DOI: $\quad$ https://doi.org/10.1016/j.carbpol.2019.115170

Article Number: $\quad 115170$

Reference: CARP 115170

To appear in:

Received Date: $\quad 25$ April 2019

Revised Date: 4 August 2019

Accepted Date: $\quad 4$ August 2019

Please cite this article as: Han L, Hu B, Ma R, Gao Z, Nishinari K, Phillips GO, Yang J, Fang Y, Effect of arabinogalactan protein complex content on emulsification performance of gum arabic, Carbohydrate Polymers (2019), doi: https://doi.org/10.1016/j.carbpol.2019.115170

This is a PDF file of an article that has undergone enhancements after acceptance, such as the addition of a cover page and metadata, and formatting for readability, but it is not yet the definitive version of record. This version will undergo additional copyediting, typesetting and review before it is published in its final form, but we are providing this version to give early visibility of the article. Please note that, during the production process, errors may be discovered which could affect the content, and all legal disclaimers that apply to the journal pertain.

(C) 2019 Published by Elsevier. 


\section{Effect of arabinogalactan protein complex content on emulsification performance of gum arabic}

Lingyu Han ${ }^{\mathrm{a}, \mathrm{b}}{ }^{\dagger}$, Bing $\mathrm{Hu}^{\mathrm{b} \dagger}{ }^{\dagger}$, Ruixiang Ma ${ }^{\mathrm{b}}$, Zhiming Gao ${ }^{\mathrm{b}}$, Katsuyoshi Nishinari ${ }^{\mathrm{b}}$, Glyn O. Phillips ${ }^{\mathrm{b}}$, Jixin Yang ${ }^{\mathrm{c}}$, and Yapeng Fang ${ }^{\mathrm{b}, \mathrm{d}^{*}}$

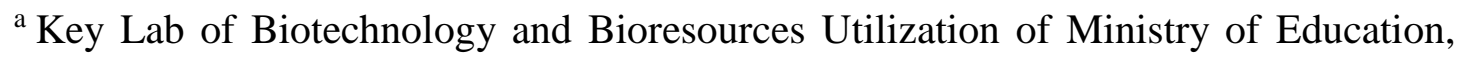
College of Life Science, Dalian Minzu University, Dalian, Liaoning, 116600, China;

${ }^{\mathrm{b}}$ Glyn O. Phillips Hydrocolloid Research Centre at HUT, School of Food and Biological Engineering, Hubei University of Technology, Wuhan 430068, China;

${ }^{\mathrm{c}}$ Faculty of Arts, Science and Technology, Wrexham Glyndwr University, Plas Coch, Mold Road, Wrexham LL11 2AW, United Kingdom;

${ }^{\mathrm{d}}$ Department of Food Science and Technology, School of Agriculture and Biology, Shanghai Jiao Tong University, Shanghai 200240, China.

*Correspondence Author:

Prof. Yapeng Fang: Department of Food Science and Technology, School of Agriculture and Biology, Shanghai Jiao Tong University, Shanghai 200240, China. Email: ypfang@sjtu.edu.cn; Tel: 86-(0)-21-34208547.

$\dagger$ These authors contributed equally to this work.

\section{Highlights}

- Phase separation induces molecular fractionation of GA/hydrocolloids mixtures. 
- Molecular fractionation increased the AGP content GA.

- Emulsifying functionality of GA improved after phase separation.

\begin{abstract}
The emulsification properties of the standard (STD), matured (EM2 and EM10) and fractionated gum arabic samples via phase separation induced molecular fractionation were investigated to find out how the content of arabinogalactan protein (AGP) complex affects the resulting emulsion properties. Phase separation and the accompanying molecular fractionation were induced by mixing with different hydrocolloids including hyaluronan (HA), carboxymethyl cellulose (CMC), and maltodextrin (MD). Increase of AGP content from 11 to $28 \%$ resulted in the formation of emulsions with relatively smaller droplet sizes and better stability. Further increase in the AGP content to $41 \%$ resulted in the formation of emulsions with larger droplets. In spite of the larger droplets sizes, these emulsions were extremely stable. In addition, the emulsions prepared with GA higher AGP content better stability in the presence of ethanol. The results indicate that AGP content plays a vital role in emulsion stability and droplet size.
\end{abstract}

\title{
Keywords:
}

gum arabic; emulsion; AGP content; emulsion stability

\section{Introduction}

Gum arabic is a naturally occurring gum made of hardened sap from the acacia trees. The gum is harvested commercially from wild trees throughout the Sahel from Senegal and Sudan to Somalia, although it has been historically cultivated in Arabia and West Asia (Verbeken, Dierckx, \& Dewettinck, 2003). Gum arabic is a complex mixture of polysaccharides and glycoproteins that has a wide range of applications in various industries and its function as stabilizers has been studied extensively (Al-Assaf et al., 2008; Alftrén et al., 2012; Pickles et al., 2007). Gum arabic is a key ingredient in traditional lithography and is used in printing, paint production, glue, 
cosmetics and viscosity control in ink and textile industries (Phillips \& Williams, 2000). In addition, Gum arabic reduces the surface tension of liquids, which leads to increased fizzing in carbonated beverages (Dikshith, 2010).

It has been shown that gum arabic consists of three fractions, i.e. arabinogalactan (AG), arabinogalactan protein complex (AGP), and glycoprotein (GP) (Randall, Phillips, \& Williams, 1988). Gum arabic has an established surface activity, being used as a stabilizer in various products, especially in food emulsions. However, due to its relatively low surface activity, a high gum/oil ratio (1:1) is required to obtain the best results (Randall et al., 1988). A recent study on adsorption of gum arabic at oil/water interface indicates that a $3 \mathrm{mg} / \mathrm{m}^{2}$ at oil/water interface is required to stabilize oil/water emulsions (Nazarzadeh, Anthonypillai, \& Sajjadi, 2013). The surface activity and emulsifying properties of gum arabic have been correlated to its AGP fraction, the structure of which is represented by a 'wattle blossom-model' and provides both hydrophobic polypeptide chain and hydrophilic carbohydrate blocks, conferring good emulsification characteristics (Castellani et al., 2010; Gomes et al., 2010). Therefore, samples with higher AGP content are more desirable (Al-Assaf et al., 2009). Natural gum arabic samples contain 10\% AGP content on average, and those obtained from old trees contain a relatively higher proportion of AGP (Ido et al., 2008; Ohm, Williams, \& Phillips, 1998; Randall et al., 1988; Randall, Phillips, \& Williams, 1989). Various approaches have been proposed to modify gum arabic samples. For instance, radiation induced cross-linking (Al-Assaf et al., 2007) and maturation (Aoki et al., 2007) have been used to enhance the emulsifying property of gum arabic. The basic principle of both methods is to increase the proportion of the AGP fraction. The maturation process (Aoki et al., 2007) can increase the AGP fraction to an average of $25 \%$, and has been widely adopted in the industry (Ogasawara et al., 2011). EM2 and EM10 are two commercial gum arabic samples modified by the maturation process. The time required for heat treatment to obtain EM10 is longer (thus a higher AGP content) than that for the production of EM2 (Castellani et al., 2010).

We have recently reported a new approach to fractionate gum arabic via phase separation induced molecular fractionation (Hu et al., 2018). This method does not require any chemical modification and the fractionation of gum arabic increased the 
content of AGP from ca. $11 \%$ to $18 \%$ in standard gum arabic (STD)/hyaluronan (HA) system from $28 \%$ to $55 \%$ in matured gum arabic (EM10)/HA system. The main purpose of current study is to characterize emulsification properties of gum arabic samples with different AGP contents following the method above in which various hydrocolloids were used to initiate phase separation system and to see how AGP content affects the resulting emulsion properties. 


\section{Experimental procedures}

\subsection{Materials}

Standard gum arabic (STD), matured gum arabic samples (EM2 and EM10), hyaluronan (HA), carboxymethyl cellulose (CMC), and maltodextrin (MD) were kindly provided by Starlight, San Ei Gen FFI, Matrix Biology Institute, CP Kelco and Avebe Food, respectively. STD has $\mathrm{M} w=55 \mathrm{kDa}$ and $\mathrm{M} w / \mathrm{M} n=1.656$; EM2 has $\mathrm{M} w$ $=285 \mathrm{kDa}$ and $\mathrm{M} w / \mathrm{M} n=4.417$; EM10 has $\mathrm{M} w=413 \mathrm{kDa}$ and $\mathrm{M} w / \mathrm{M} n=8.028 ; \mathrm{HA}$ has $\mathrm{M} w=168 \mathrm{kDa}$ and $\mathrm{M} w / \mathrm{M} n=2.541 ; \mathrm{CMC}$ has $\mathrm{M} w=27 \mathrm{kDa}$ and $\mathrm{M} w / \mathrm{M} n=$ 1.791; and $\mathrm{MD}$ has $\mathrm{M} w=79 \mathrm{kDa}$ and $\mathrm{M} w / \mathrm{M} n=10.362$. Ethanol $(\mathrm{Et}-\mathrm{OH})$, and sodium chloride $(\mathrm{NaCl})$ were obtained from Fischer Scientific, UK and medium-chain triglyceride (MCT) oil was purchased from Trec Nutrition Company, Poland.

\subsection{Fractionation}

Mixing two biopolymers in a common solvent may result in phase separation, either associative or segregative. Effects of temperature and solvent condition on segregative phase separation-induced molecular fractionation of gum arabic/hyaluronan mixed solutions were investigated in a previous study (Hu et al., 2018). Fractionation of gum arabic increased the content of arabinogalactan-protein complex (AGP) in both STD/HA and EM10/HA systems. In this study, fractionated samples were prepared using HA, CMC and MD as described in the previous paper (Hu et al., 2018). Stock solutions were prepared containing 5, 6 and $20 \mathrm{w} / \mathrm{v} \%$ matured gum and $0.25 \mathrm{w} / \mathrm{v} \%$ $\mathrm{HA}, 0.75 \mathrm{w} / \mathrm{v} \% \mathrm{CMC}$ and $15 \mathrm{w} / \mathrm{v} \% \mathrm{MD}$, respectively (the concentrations of mixtures were selected from the corresponding phase diagrams according to the previous research by Hu et al. (2018)). The solutions were then centrifuged for $3 \mathrm{~h}$ at $4000 \mathrm{rpm}$ (ThermoHeraeus Multifuge X1R, Thermo Fisher, USA). Phase separation was observed after the centrifugation, and AGP rich fraction was characterized using the GPC-MALLS system as described below. All solutions contained sodium azide $(0.005$ $\mathrm{w} / \mathrm{v} \%$ of total solution) as a preservative.

\subsection{GPC-MALLS measurements}

Gum arabic samples were evaluated by measuring the molecular weight distribution using gel permeation chromatography-multiangle laser light scattering (GPC-MALLS) 
as described in the previous reports (Aoki et al., 2007; Hu et al., 2018). A Superose 6 10/300GL column was used to determine the molecular weight, and fractionation for the standard, matured and fractionated gum arabic samples using an Agilent 1100 series UV detector (Agilent Technologies, USA) operating at $214 \mathrm{~nm}$, a DAWN EOS multiangle light scattering detector (Wyatt Technology Corporation, USA) operating at $690 \mathrm{~nm}$, and an Optilab refractometer (Wyatt Technology Corporation, USA). Aqueous $\mathrm{NaCl}$ solution $(0.2 \mathrm{M})$ with $0.5 \mathrm{mg} / \mathrm{ml}$ sodium azide filtered through $0.2 \mu \mathrm{m}$ Millipore filter was adopted as an eluent and delivered at a constant rate of 0.4 $\mathrm{mL} / \mathrm{min}$ by a Waters 515 HPLC pump (Waters Co., Massachusetts, USA). The test material was prepared in the same solvent at a concentration of $2 \mathrm{mg} / \mathrm{mL}$. It was injected into the GPC-MALLS system after being filtered using a $0.45 \mu \mathrm{m}$ Nylon filter. Data were collected and analyzed by Astra 4.90.08 software.

\subsection{Emulsification}

The emulsions were prepared in this work was according to the method of Cirre et al. (2014). The emulsions contain $0.12 \mathrm{w} / \mathrm{v} \%$ citric acid (to adjust the $\mathrm{pH}$ to $\sim 4$ ), 0.13 w/v\% benzoic acid (as a preservative), MCT oil used as model oil and various gum arabic samples used as stabilizers. The ratios of gum arabic to MCT oil are given in Table 1. The ingredients were initially mixed using a high shear homogenizer (Polytron PT-2100) at $26000 \mathrm{rpm} / \mathrm{min}$ for $3 \mathrm{~min}$ followed by three passes through a high-pressure homogenizer at 75MPa (Nanomizer, NM II, Yoshida, Japan).

\subsection{Droplet size measurement}

The mean droplet diameters (Sauter mean diameter $\mathrm{d}_{3,2}$ \& volume weighted mean diameter $\mathrm{d}_{4,3}$ ) and droplet size distribution by volume of emulsions were measured using a Mastersizer 2000 (Malvern, UK). Three consecutive measurements were performed on each run and the average was reported (within 3\% error). The droplet size measurement was performed both after $1 \mathrm{~h}$ storage at room temperature $\left(20 \pm 2^{\circ} \mathrm{C}\right)$ and after 3 days at accelerated conditions of $60^{\circ} \mathrm{C}$ in a convection oven (thermal stress acceleration test), in order to evaluate the stability of the emulsions. Previous studies have shown that 3 days storage at $60^{\circ} \mathrm{C}$ to be equivalent to six months storage at room temperature (Al-Assaf et al., 2008). 


\subsection{Surface coverage}

The surface coverage of droplets $(\theta)$ was calculated using the BET isotherm as described in earlier reports (Nazarzadeh et al., 2013). The BET isotherm is given as

$$
\theta=\frac{K_{B} C_{e}}{\left(C_{s}-C_{e}\right)\left\{1+\left(K_{B}-1\right)\left(C_{e} / C_{s}\right)\right\}}
$$

Equation 1

where $\theta, C_{e}, C_{s}$ and $K_{B}$ are fractional surface coverage, the saturation concentration of stabilizer at the interface $(\mathrm{mg} / \mathrm{ml})$, equilibrium (i.e. non-adsorbed) concentration of stabilizer in aqueous solution $(\mathrm{mg} / \mathrm{ml})$, and the BET isotherm constant, respectively.

The adsorbed fraction of the gum arabic at the interface $\left(C_{a}\right)$ is given by

$$
C_{a}=\frac{\theta S}{a} V_{e}
$$

Equation 2

where $\mathrm{S}, V_{e}$, and $a$ are total area of droplets (i.e. interfacial area, $\mathrm{m}^{2}$ ), volume of emulsion $(\mathrm{mL})$, and the surface packing area occupied per $\mathrm{mg}$ of stabilizer $\left(\mathrm{m}^{2} / \mathrm{mg}\right)$, respectively. The saturation concentration of stabilizer, surface packing area and BET isotherm contestant for gum arabic were found to be $200 \mathrm{mg} / \mathrm{mL}, 1.27 \mathrm{~m}^{2} / \mathrm{mg}$ and 9.55 (Nazarzadeh et al., 2013), respectively. Equations 1 and 2 were simultaneously solved, using an overall mass balance for the gum arabic as $C_{t}=C_{e}+C_{a}$ to find the adsorbed and non-adsorbed fractions.

\section{Results and discussion}

\subsection{Effect AGP content}

The role of AGP fraction on the emulsification performance and stability was examined by comparing STD, matured (EM2 and EM10) and HA fractionated gum arabic samples. Emulsions were prepared as described in the experimental section using two gum/oil ratios as 1:1 and 1: 2 for standard and matured gum arabic samples, and higher oil concentration for fractionated gum arabic samples. The experimental conditions and measured droplet sizes are presented in Table 1 and Figure 1. As mentioned earlier, it has been well established that 1:1 gum/oil ratio is required to produce a stable emulsion. The main differences between emulsions are significantly 
larger $\mathrm{d}_{4,3}$ and higher $\%>1 \mu \mathrm{m}$ (percentage of droplet size $>1 \mu \mathrm{m}$ ) for the ones produced with higher oil concentrations. Also, matured gums result in the formation of relatively smaller $d_{3,2}$. These are clearly shown in the droplet size distribution of formed emulsions (Figure 1a). Similar results were reported by Xiang et al. Their study dealt with the interfacial adsorption of three gum arabic samples (one conventional gum, GA; two matured gums, EM2 and EM10) at the conjugated linoleic acid (CLA)-water interface, in relation to their emulsifying properties. Among the three gums, EM10 exhibited the highest emulsifying activity and conferred the best emulsion stability, despite its lowest surface load. This is presumably due to a larger tendency of the AGP fraction in EM10 toward aggregation at the CLA-water interface (Xiang et al., 2015). The droplet size distribution of HA fractionated gum arabic samples was shown in Figure 1b. The emulsions formed by HA fractionated gum arabic samples compared with that of EM10 have a similar droplet size at the same gum/oil ratio $(1: 2)$; however it can stabilize higher gum/oil ratios (from $1: 2$ to $2: 9)$ emulsions due to the AGP content of HA fractionated gum arabic being higher than $41 \%$. The final droplet size of an emulsion is the result of concurrent droplet rupture and coalescence. Formation of large droplets and high fraction of droplets larger than $1 \mu \mathrm{m}$, in emulsions having high oil phase ratios, can be attributed to higher coalescence rate as discussed in the previous publications (Nazarzadeh \& Sajjadi, 2010, 2013; Walstra, 1993).

Table 1. AGP content of various gum arabic samples and mean volume and surface droplet sizes and fractions higher than $1 \mu \mathrm{m}$ for emulsions with different gum/oil ratios.

\begin{tabular}{|c|c|c|c|c|c|c|c|c|}
\hline Sample type & $\begin{array}{l}\mathrm{Mw} \\
(\mathrm{g} / \mathrm{mol})^{\mathrm{a}}\end{array}$ & $\begin{array}{l}\text { AGP } \\
\text { content } \\
(\%)^{\mathrm{a}}\end{array}$ & $\begin{array}{l}\text { Gum } \\
\text { arabic } \\
(\%)\end{array}$ & $\begin{array}{l}\text { MCT } \\
\%\end{array}$ & $\begin{array}{l}\text { Gum/Oil } \\
\text { ratio }\end{array}$ & $\mathrm{D}[\mathbf{3 , 2}]$ & D $[4,3]$ & $\begin{array}{l}\%> \\
1.0 \\
\mu \mathrm{m}\end{array}$ \\
\hline \multirow{2}{*}{ STD } & \multirow{2}{*}{$0.55 \times 10^{6}$} & \multirow{2}{*}{11} & 10 & 10 & $1: 1$ & 0.45 & 0.67 & 1.96 \\
\hline & & & 5 & 10 & $1: 2$ & 0.46 & 1.10 & 29.85 \\
\hline \multirow{2}{*}{ EM2 } & \multirow{2}{*}{$2.85 \times 10^{6}$} & \multirow{2}{*}{17.9} & 10 & 10 & $1: 1$ & 0.31 & 0.60 & 2.01 \\
\hline & & & 5 & 10 & $1: 2$ & 0.55 & 1.01 & 27.46 \\
\hline \multirow{2}{*}{ EM10 } & \multirow{2}{*}{$4.13 \times 10^{6}$} & \multirow{2}{*}{28} & 10 & 10 & $1: 1$ & 0.29 & 0.47 & 1.60 \\
\hline & & & 5 & 10 & $1: 2$ & 0.72 & 0.82 & 24.28 \\
\hline$\overline{\mathrm{HA}}$ & $4.92 \times 10^{6}$ & 41 & 5 & 10 & $1: 2$ & 0.79 & 1.16 & 35.33 \\
\hline
\end{tabular}




\begin{tabular}{|l|l|l|l|l|l|l|l|l|}
\hline $\begin{array}{l}\text { fractionated } \\
\text { EM10 }\end{array}$ & & 4 & 9 & $4: 9$ & 0.81 & 1.16 & 37.32 \\
\cline { 4 - 9 } & & 3 & 9 & $1: 3$ & 0.94 & 1.36 & 49.62 \\
\cline { 4 - 9 } & 2 & 9 & $2: 9$ & 1.07 & 1.49 & 61.00 \\
\hline $\begin{array}{l}\text { CMC } \\
\text { fractionated } \\
\text { EM10 }\end{array}$ & $4.81 \times 10^{6}$ & 41 & 5 & 10 & $1: 2$ & 0.43 & 0.86 & 35.06 \\
\cline { 4 - 9 } & & 2 & 10 & $1: 5$ & 0.47 & 1.47 & 62.6 \\
\hline $\begin{array}{l}\text { MD } \\
\text { fractionated } \\
\text { EM10 }\end{array}$ & $3.82 \times 10^{6}$ & 33 & 7 & 14 & $1: 2$ & 0.43 & 0.66 & 11.91 \\
\cline { 3 - 9 } & & 2 & 14 & $1: 7$ & 1.19 & 1.58 & 70.18 \\
\hline
\end{tabular}

a: The molecular weight and AGP content of different GA and fractionated GA were measued by GPC-MALLS. Measurements were carried out using the same conditions employed for GA as described previously by Aoki et al. (2007). The light scattering and refractive index response two distinctive peaks. The first peak has a high response since it corresponds to the high molecular weight material (AGP) content.
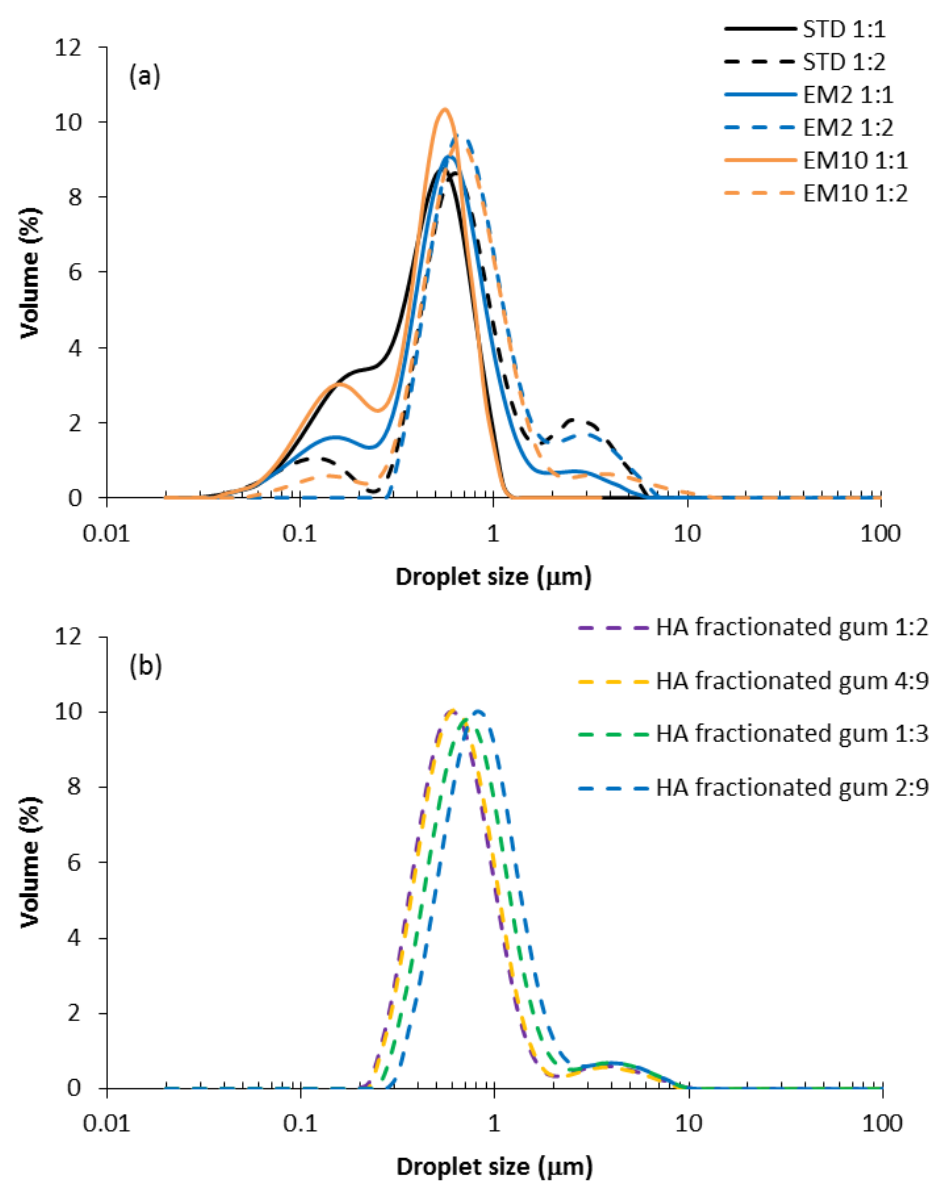
Figure 1. Droplet size distributions of emulsions produced using STD and mature gum arabic samples at various ratios of gum/oil (a) and (b) emulsions produced using HA fractionated gum arabic samples at various ratios of gum/oil.

The stability of emulsions was tested by thermal acceleration at $60^{\circ} \mathrm{C}$ for 3 and 7 days. Figure 2 shows variations in droplet size distribution of emulsions stabilized by STD and matured gum samples at 1:1 and 1:2 gum/oil ratios. The emulsion produced with matured gum at 1:1 gum/oil ratio was found to be the most stable (Figure 2a), while increasing gum/oil ratio to 1:2 resulted in an increase in large droplets after 7 days (Table 1 and Figure 2b). However, emulsions stabilized with STD gum arabic sample were less stable, especially when the oil concentration was higher. These results indicate that the matured gum having a higher proportion of AGP fraction provides better emulsification and stability compared to STD gum.
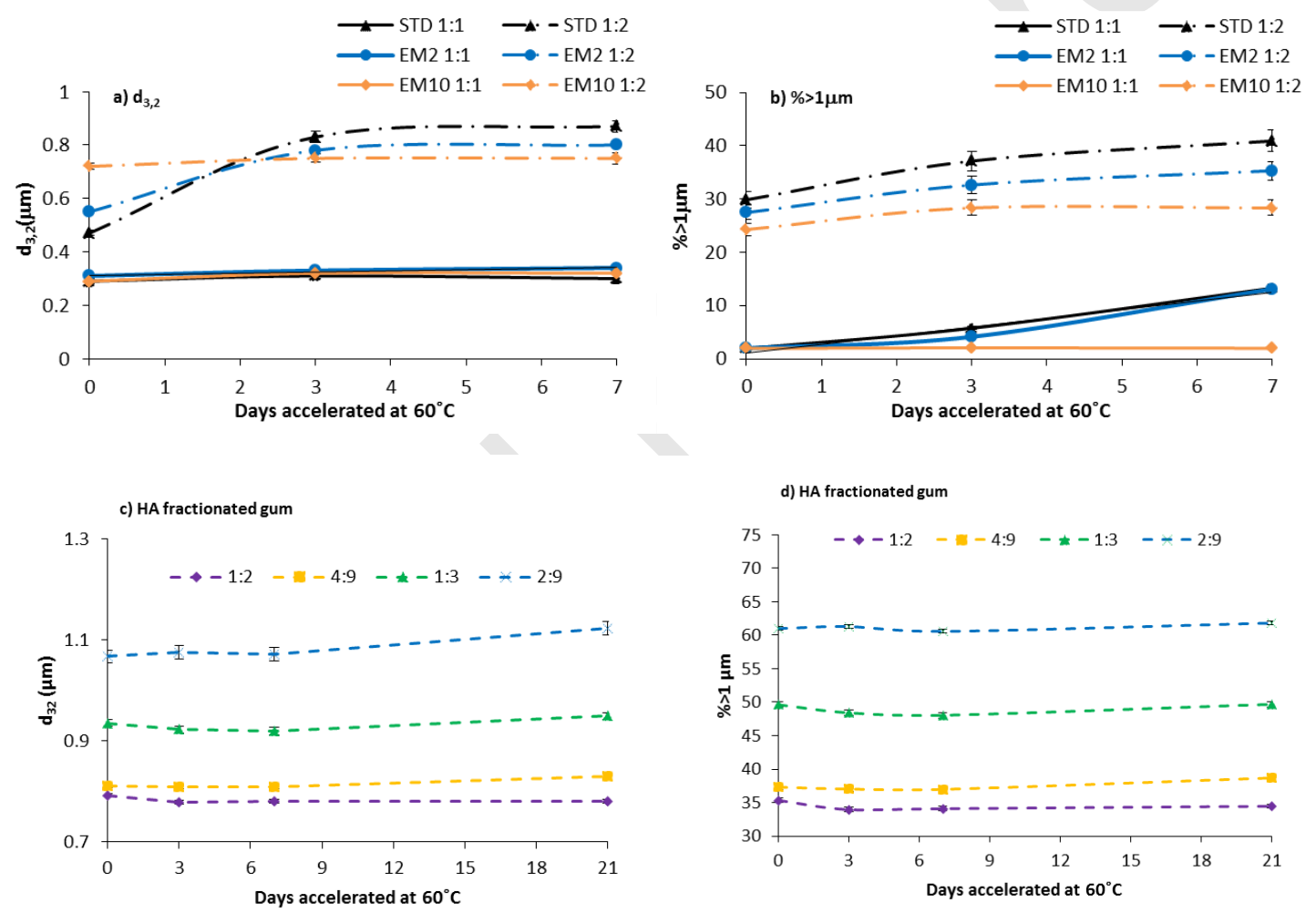

Figure 2. Variations in a) $d_{3,2}$ and b) $\%>1 \mu \mathrm{m}$ of STD and matured gum; c) $d_{3,2}$ and d) $\%>1 \mu \mathrm{m}$ of HA fractionated gum stabilized emulsions at various gum/oil ratios, after acceleration for 7 and 21 days at $60^{\circ} \mathrm{C}$.

To further investigate the effect of AGP on formation and stabilization of droplets, a series of experiments were also conducted using an AGP rich phase, produced by HA 
fractionation. Figure $1 \mathrm{~b}$ shows droplet size distribution of emulsions produced with fractionated (AGP rich) gum arabic samples. The resulting emulsions, in comparison with STD and matured gum samples, did not have a peak of small droplets (in range $0.2 \mu \mathrm{m}$ ) but showed relatively higher proportion of larger droplets. Increasing gum/oil ratio to 2:9 resulted in the formation of larger droplets, and a shift to the right for the main peak while no small stable droplet was detected in the emulsion. The presence of small droplets in emulsions stabilized by matured and STD gums indicates formation of satellite droplets during emulsification time (Nazarzadeh et al., 2010). This shows that the AG and GP fractions, having lower Mw, are responsible for stabilization of these small/satellite droplets. However, the AGP fraction, being a larger molecule, cannot stabilize the droplets of small size (Hirose et al., 2006).

Figures $2 \mathrm{c}$ and $2 \mathrm{~d}$ show the results from thermal acceleration of emulsions produced with fractionated AGP rich gum arabic samples at various gum/oil phase ratios. These emulsions were very stable and no changes in $\mathrm{d}_{3,2}$ and $\%>1 \mu \mathrm{m}$ were observed during 7 days acceleration at $60^{\circ} \mathrm{C}$. It is worth noting that even after extending the acceleration test to very harsh 21 days, only a small change in droplet size was observed for the emulsions with high oil concentrations (i.e. gum/oil ratios of 1:3 and 2:9) while emulsions with lower oil concentration were stable during this time. The estimated surface coverage of emulsions is presented in Figure 3. The results show $100 \%$ and 55\% surface coverage for emulsions stabilized with STD gum at 1:1 and 1:2 ratios, respectively. This clearly explains the lower stability of emulsion at 1:2 ratio, compared to the fully covered 1:1 ratio emulsion sample. The estimated surface coverage of matured and fractionated gum samples is relatively lower than those of STD gum and in range of $90 \%$ for $1: 1$ ratio and $70 \%$ and lower for other gum/oil ratios. Despite their lower estimated surface coverage, these samples show a very good stability compared to STD gum. This excellent stability of emulsions can be attributed to the higher content of AGP which confers a thicker interfacial layer and provides more effective steric stabilizing effect, due to the larger hydrodynamic size of the AGP fraction (Dickinson, 2003; Dickinson et al., 1991). Meanwhile, as suggested by the previous research (Nakauma et al., 2008), the GA emulsion stability will be affected by the $\mathrm{pH}$ values due to the zeta potential of GA. The zeta potential decreases rapidly at $\mathrm{pH}$ below 3.0, while in the higher $\mathrm{pH}$ regime (>3.0), it is much less $\mathrm{pH}$-dependent. In addition, the surface packing area used for the estimation was 
obtained for a gum having 13\% AGP content. For gum arabic samples having higher AGP content and higher $\mathbf{M}_{w}$, the surface packing area is expected to be larger. Also, the AGP fraction was a coiled structure. Once attached to the interface, it can start spreading over the interface and the protein content can penetrate the oil phase at multiple positions, providing a perfect anchoring to the interface that increases the energy required for de-sorption. These results show that an AGP rich solution can stabilize a high concentration of oil (up to 4 times higher than the gum concentration).

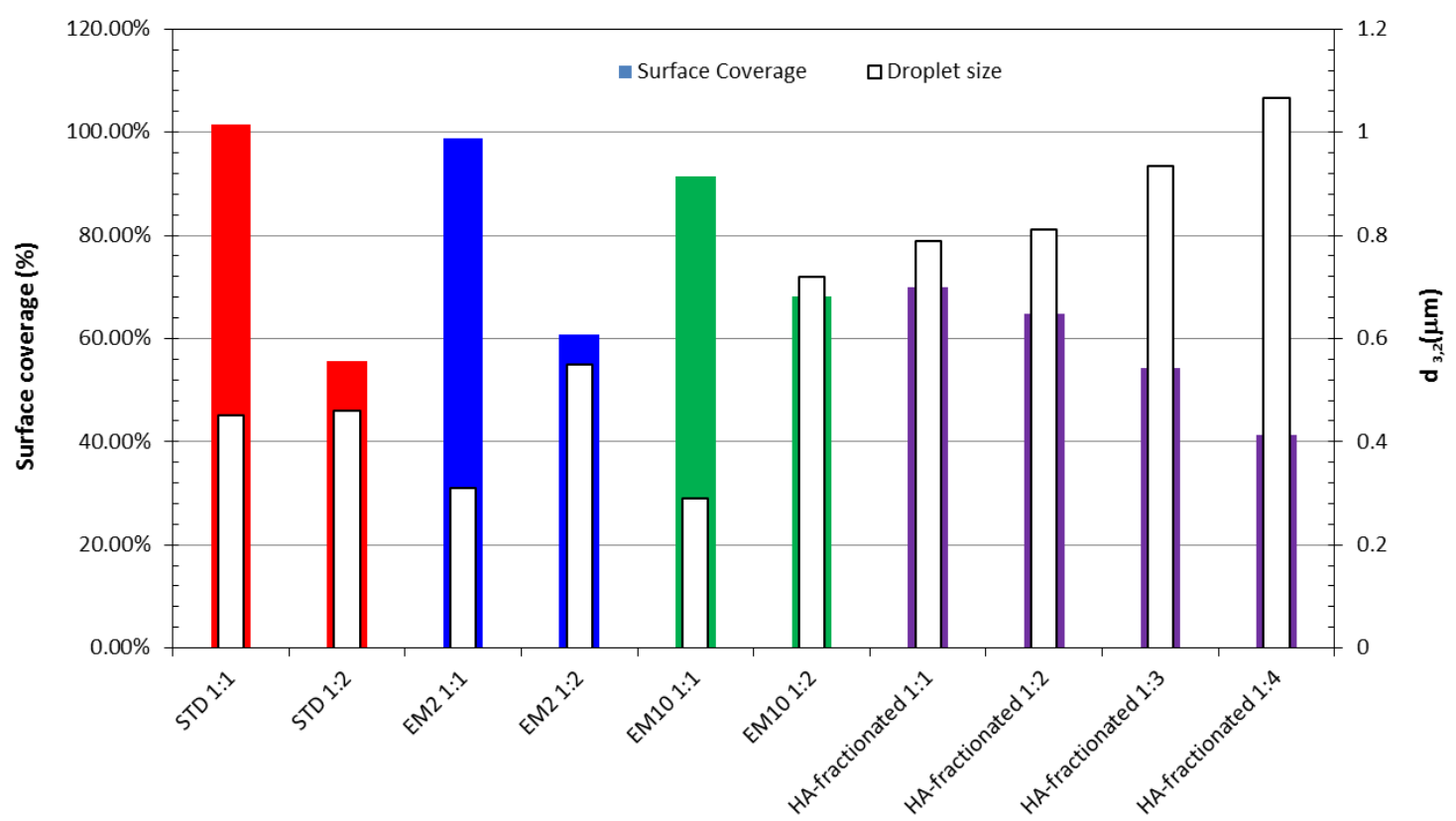

Figure 3. Estimated surface coverage of emulsions stabilized with different gum arabic samples and gum/oil ratios. HA is for gum samples fractionated with hyaluronan.

\subsection{Effects of fractionation initiated by different hydrocolloids}

In order to further explore the effect of AGP on formation and stabilization of emulsions, AGP rich fractions obtained through phase separation induced by carboxymethyl cellulose (CMC), and maltodextrin (MD) were also investigated. The obtained phases had $41 \%$ and 33\% AGP fraction using CMC and MD as fractionators, respectively. Previous studies of our research group investigated the phase separation and phase separation-induced fractionation of GA/sugar beet pectin mixed solutions. Fractionation of GA increased the content of AGP from ca. 13\% to 27\%. The fractionated GA showed improved emulsifying functionality, whereas the fractionated 
sugar beet pectin had a reduced emulsifying functionality (Mao et al., 2013). The difference in the increase in AGP content after phase separation induced fractionation in different mixed systems is mainly due to complex factors such as biopolymer concentrations, molecular weight, charge, shape and conformation etc. In the current work, the emulsions produced from these AGP rich fraction samples showed a peak of small droplets at $0.1 \mu \mathrm{m}$ (Figures $4 \mathrm{c}$ and $4 \mathrm{~d}$ ) and a smaller surface average droplet size $\left(\mathrm{d}_{3,2}\right)$ and $\%>1 \mu \mathrm{m}$ (Figures $4 \mathrm{a}$ and $4 \mathrm{~b}$ ), compared to HA fractionated and matured gum arabic samples. Formation and stabilization of small droplets (the peak of small droplets) can be attributed to the presence of CMC and MD in AGP rich fractions. GPC elution profiles of fractionated gum, obtained from CMC and MD, indicate the presence of around 2\% MD in the AGP rich phase (Hu et al., 2018). Both CMC and MD are common stabilizers in food emulsions (Dokic-Baucal et al., 2004). Increasing the gum/oil ratios to 1:5 and 1:7 for the CMC and MD fractioned gums, respectively, resulted in the formation of large droplets and significant increase in the fraction of droplets larger than $1 \mu \mathrm{m}$ (Figures $4 \mathrm{a}$ and $4 \mathrm{~b}$ ). This indicates a higher coalescence rate during emulsification as discussed earlier for lower gum/oil ratios.

The resulting emulsions from CMC fractionated gum showed excellent stability against thermal acceleration, and no changes in $d_{3,2}$ and $\%>1 \mu \mathrm{m}$ were observed (Figures 4a, 4b and 4d). However, by looking at the variations in droplet size distribution of MD fractionated gum arabic samples in Figure 4c, the peak of small droplet disappeared after 3 days, albeit it remained stable after 3 days acceleration. The better stability of CMC fractionated gum samples might be due to higher AGP content, which might also be the reason for slightly larger droplet size and higher $\%>1 \mu \mathrm{m}$. MD and CMC may act as emulsifiers or as texture modifiers. GAs are surface-active ingredients that adsorb to the surface of emulsion droplets and prevent them from aggregating. MD and CMC increase the viscosity of the continuous phase of emulsions which slows down the gravitational separation of the droplets. Therefore, the main stabilizing action for these is believed to be through viscosity modification of the aqueous continuous phase surrounding the oil droplets (Dickinson, 2003). 

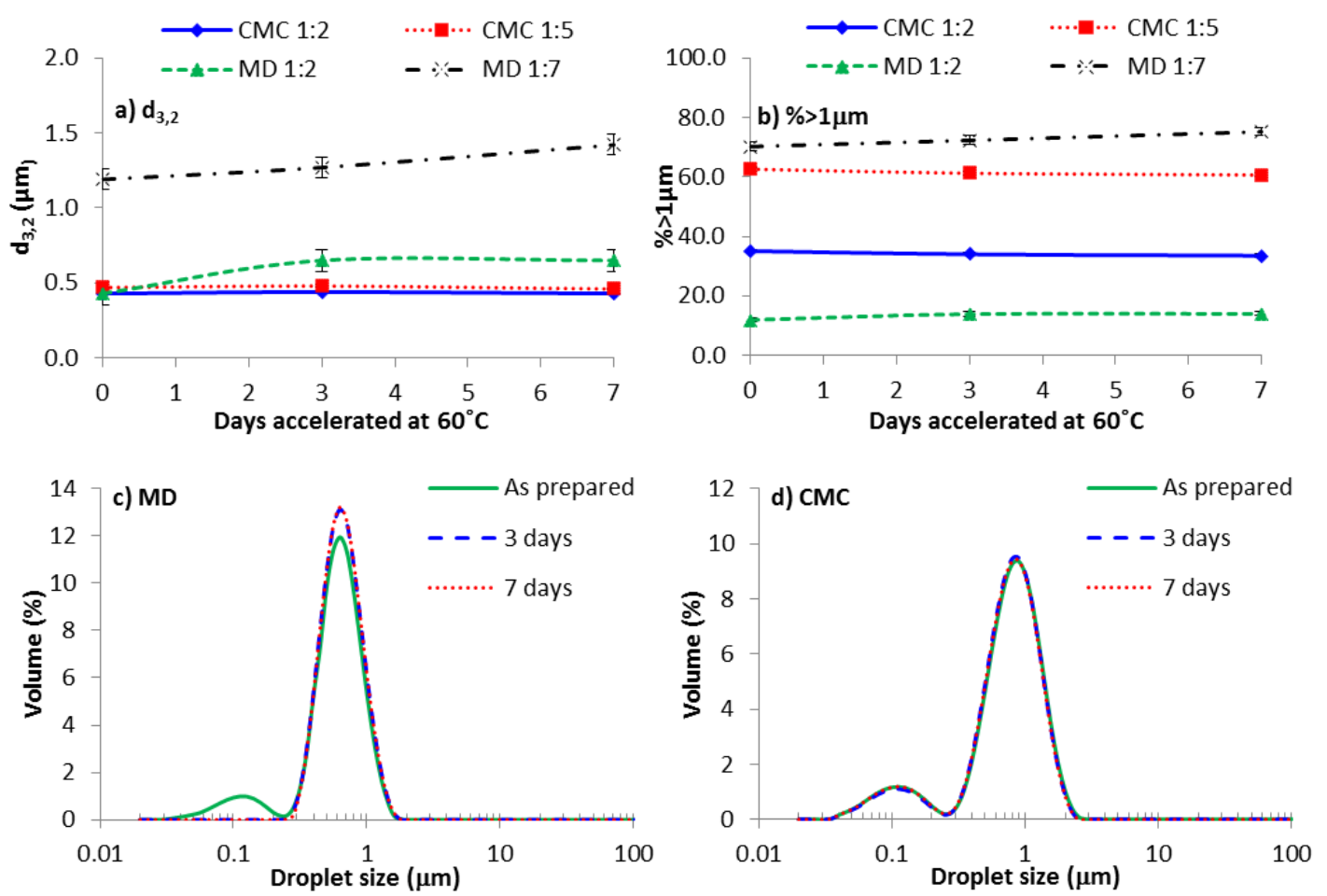

Figure 4. Temporal variation in a) $d_{3,2}$ and b) $\%>1 \mu m$ of emulsions produced using CMC and MD fractionated gums; temporal variations in droplet size distribution of emulsions stabilized with AGP rich phases fractionated with c) MD; and d) CMC after acceleration for 3 and 7 days at $60^{\circ} \mathrm{C}$.

\subsection{Effects of ethanol}

Gum arabic is widely used as a stabilizer in beverage industry (Tipvarakarnkoon et al., 2010), which includes alcoholic drinks. Therefore, the effect of ethanol on gum arabic stabilized emulsions is of significant importance. In order to compare the effect of AGP content on emulsification, two emulsions with matured and fractionated gum arabic samples were prepared in the presence in $10 \mathrm{w} / \mathrm{v} \%$ ethanol of total emulsion.

Figure 5 shows temporal evolution of droplet size and droplet size distribution of the emulsions containing $10 \mathrm{w} / \mathrm{v} \%$ ethanol. Cross comparison between graphs in Figures $5 \mathrm{a}$ and $5 \mathrm{~b}$ with Figures $2 \mathrm{c}$ and $2 \mathrm{~d}$ shows that the presence of alcohol resulted in the formation of significantly larger droplets for both gum arabic samples. The fraction of droplets larger than $1 \mu \mathrm{m}$ in the presence of ethanol was twice of that in alcohol free emulsions under the same condition (Figure $2 \mathrm{~d}$ and Figure 5b). Furthermore, variations in droplet size distribution for emulsions in the presence of ethanol indicated a less stable emulsion, in comparison to the alcohol free samples. The peak 
of small droplets for matured gum stabilized emulsions disappeared after three days. Fractionated gum stabilised emulsion showed a better stability in the presence of ethanol; however, the presence of large droplets was detected after thermal acceleration for 7 days. These results are in line with the previous reports that show larger and less stable hydrocolloids stabilized emulsions in the presence of alcohol (Burgaud \& Dickinson, 2010; Dickinson \& Woskett, 1988).
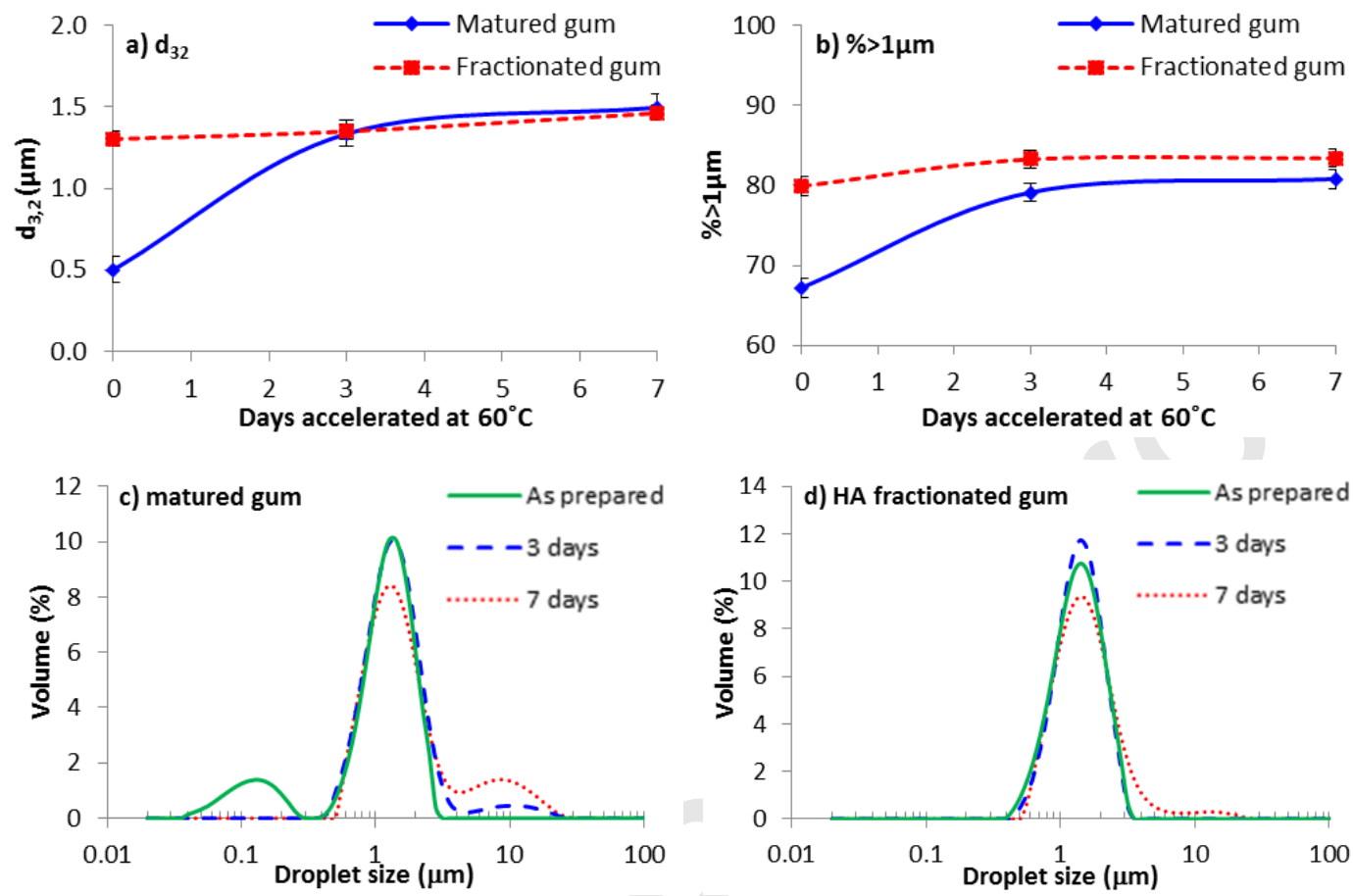

Figure 5. Variations in a) $d_{3,2}$, b) $\%>1 \mu \mathrm{m}$ of emulsions and droplet size distributions of emulsions produced by c) EM10 and d) fractionated EM10 samples at gum/oil phase ratio of 1:2, containing $10 \mathrm{w} / \mathrm{v} \%$ ethanol, after thermal acceleration for 3 and 7 days at $60^{\circ} \mathrm{C}$.

Surface coverage estimations for the emulsion in the presence of alcohol were not calculated as it was believed that the presence of alcohol would affect surface activity and surface adsorption of gum arabic significantly. Besides, the available surface packing and adsorption constants are not valid for this system. The presence of alcohol can affect the system in two ways. Ethanol increases the solubility of oil in the aqueous phase and also decreases the oil/water interfacial tension. This favors droplet rupture, producing small droplets (Wójcik et al., 1989). However, low interfacial tension can also promote droplet coalescence, increasing the droplet size in the absence of a good stabilizer. In addition to lowering the interfacial tension, the presence of ethanol in the aqueous phase influences the protein molecular structure 
and the state of protein aggregation, both in the bulk solution and at the fluid interface (Ahmed, et al., 1990). Ethanol modifies protein structure and interaction properties through specific binding=accompanied by dehydration (Bull \& Breese, 2010), and protein denaturation increases with increasing ethanol concentration (Brody \& Leautey, 2010). The emulsifying and stabilization properties of gum arabic are correlated to its protein content and therefore the presence of ethanol can inhibit adsorption of gum arabic as suggested in the previous studies (Isabelle \& Eric, 1990).

\section{Conclusions}

An increase in the AGP fraction of gum arabic from 11 to $28 \%$ showed emulsions with relatively smaller droplet sizes and better stability. Further increase in the AGP content to $41 \%$ resulted in the formation of stable emulsions with larger droplets of $>1 \mu \mathrm{m}$, reflecting the effect of higher AGP fractions. The presence of ethanol affected the surface adsorption of gum arabic at the interface.

\section{Acknowledgements}

This work was supported by National Natural Science Foundation of China (No. 31701555 and No. 31671811), doctor launching fund of Hubei University of Technology (BSQD2017023 and BSQD2017024), the state key research and development plan "modern food processing and food storage and transportation technology and equipment" (No. 2017YFD0400200) and the grant from Shanghai Science and Technology Committee (No. 18JC1410801). 


\section{References}

Al-Assaf, S., Cirre, J., Andres-Brull, M., Sakata, M., Mckenna, C., Grimsey, J., \& Phillips, G. O. (2008). Correlation of gum arabic molecular weight parameters with emulsification performance. Foods \& food ingredients journal of Japan, 213, 377-383.

Al-Assaf, S., Phillips, G. O., Williams, P. A., \& du Plessis, T. A. (2007). Application of ionizing radiations to produce new polysaccharides and proteins with enhanced functionality. Nuclear Instruments \& Methods in Physics Research Section B-Beam Interactions with Materials and Atoms, 265(1), 37-43.

Al-Assaf, S., Sakata, M., Mckenna, C., Aoki, H., \& Phillips, G. O. (2009). Molecular associations in acacia gums. Structural Chemistry, 20(2), 325-336.

Alftrén, J., Peñarrieta, J. M., Bergenståhl, B., \& Nilsson, L. (2012). Comparison of molecular and emulsifying properties of gum arabic and mesquite gum using asymmetrical flow field-flow fractionation. Food Hydrocolloids, 26(1), 54-62.

Aoki, H., Al-Assaf, S., Katayama, T., \& Phillips, G. O. (2007). Characterization and properties of Acacia senegal (L.) Willd. var. senegal with enhanced properties (Acacia (sen) SUPER GUM (TM)): Part 2 - Mechanism of the maturation process. Food Hydrocolloids, 21(3), 329-337.

Aoki, H., Katayama, T., Ogasawara, T., Sasaki, Y., Alassaf, S., \& Phillips, G. O. (2007). Characterization and properties of Acacia senegal (L.) Willd. var. senegal with enhanced properties (Acacia (sen) SUPER GUM). Part 5. Factors affecting the emulsification of Acacia senegal and Acacia (sen) SUPER GUM. Food Hydrocolloids, 21(3), 338-346.

Brody, E. N., \& Leautey, J. (2010). Transcription in vitro using mixtures of ethylene glycol and water. FEBS Journal, 36(2), 347-361.

Bull, H. B., \& Breese, K. (2010). Interaction of alcohols with proteins (p\&nbsp;2121-2131). Biopolymers, 17(9), 2121-2131.

Burgaud, I., \& Dickinson, E. (2010). Emulsifying effects of food macromolecules in presence of ethanol. Journal of Food Science, 55(3), 875-876.

Castellani, O., Guibert, D., Alassaf, S., Axelos, M., Phillips, G. O., \& Anton, M. (2010). Hydrocolloids with emulsifying capacity. Part 1 - Emulsifying properties and interfacial characteristics of conventional (Acacia senegal (L.) Willd. var. senegal) and matured (Acacia (sen) SUPER GUMTM) Acacia senegal. Food Hydrocolloids, 24(2), 193-199.

Dickinson, E. (2003). Hydrocolloids at interfaces and the influence on the properties of dispersed systems. Food Hydrocolloids, 17(1), 25-39.

Dickinson, E., Galazka, V. B., \& Anderson, D. M. W. (1991). Emulsifying behaviour of gum arabic. Part 1: Effect of the nature of the oil phase on the emulsion droplet-size distribution. Carbohydrate Polymers, 14(4), 373-383.

Dickinson, E., \& Woskett, C. M. (1988). Effect of alcohol on adsorption of casein at the oil—water interface. Food Hydrocolloids, 2(3), 187-194.

Dikshith, T. T. S. (2010). Handbook of Chemicals and Safety.

Dokic-Baucal, L., Dokic, P., \& Jakovljevic, J. (2004). Influence of different maltodextrins on properties of O/W emulsions. Food Hydrocolloids, 18(2), 233-239.

Gomes, J. F., Rocha, S., Do, C. P. M., Peres, I., Moreno, S., Toca-Herrera, J., \& Coelho, M. A. (2010). Lipid/particle assemblies based on maltodextrin-gum arabic core as bio-carriers. Colloids \& Surfaces B Biointerfaces, 76(2), 449-455.

Hirose, Y., Ogasawara, T., Nakamura, M., Sakata, M., \& Al-Assaf, S. (2006). Estimation of 
concentration and performance of AGPs in emulsion systems using gum arabic. International Forum on Arabinogalactan Protein, 211, 222-227.

Hu, B., Han, L., Gao, Z., Zhang, K., Alassaf, S., Nishinari, K., Phillips, G. O., Yang, J., \& Fang, Y. (2018). Effects of temperature and solvent condition on phase separation induced molecular fractionation of gum arabic/hyaluronan aqueous mixtures. International Journal of Biological Macromolecules, 116, 683-690 .

Ido, T., Ogasawara, T., Katayama, T., Sasaki, Y., Al-Assaf, S., \& Phillips, G. O. (2008). Emulsification Properties of GATIFOLIA (Gum Ghatti) Used for Emulsions in Food Products. FFI Journal, 213, 365-371.

Isabelle, B., \& Eric, D. (1990). Emulsifying effects of Food Macromolecules In Presence of Ethanol.

Mao, P., Zhao, M., Zhang, F., Fang, Y. P., Phillips, G. O., Nishinari, K., \& Jiang, F. (2013). Phase separation induced molecular fractionation of gum arabic-Sugar beet pectin systems. Carbohydrate Polymers, 98(1), 699-705.

Nakauma, M., Funami, T., Noda, S., Ishihara, S., Al-Assaf, S., Nishinari, K., \& Phillips, G. O. (2008). Comparison of sugar beet pectin, soybean soluble polysaccharide, and gum arabic as food emulsifiers. 1. Effect of concentration, $\mathrm{pH}$, and salts on the emulsifying properties. Food Hydrocolloids, 22(7), 1254-1267.

Nazarzadeh, E., Anthonypillai, T., \& Sajjadi, S. (2013). On the growth mechanisms of nanoemulsions. Journal of Colloid \& Interface Science, 397(5), 154-162.

Nazarzadeh, E., \& Sajjadi, S. (2010). Viscosity effects in miniemulsification via ultrasound. Aiche Journal, 56(10), 2751-2755.

Nazarzadeh, E., \& Sajjadi, S. (2013). Thermal Effects in nanoemulsification by ultrasound. Industrial \& Engineering Chemistry Research, 52(28), 9683-9689.

Ogasawara, N., Sasaki, M., Itoh, Y., Tokudome, K., Kondo, Y., Ito, Y., Tanida, S., Kamiya, T., Kataoka, H., \& Joh, T. (2011). Rebamipide suppresses TLR-TBK1 signaling pathway resulting in regulating IRF3/7 and IFN- $\alpha / \beta$ reduction. Journal of Clinical Biochemistry \& Nutrition, 48(2), 154-160.

Ohm, I., Williams, P. A., \& Phillips, G. O. (1998). Characterisation of gum from Acacia senegal trees of different age and location using multidetection gel permeation chromatography. Food Hydrocolloids, 12(4), 379-388.

Phillips, G. O., \& Williams, P. A. (2000). Handbook of hydrocolloids. (Starch. Cambridge, England, Woodhead Publishing limited.)

Pickles, N. A., Aoki, H., Al-Assaf, S., Sakata, M., Ogasawara, T., Ireland, H. E., Coleman, R. C., Phillips, G. O., \& Williams, J. H. H. (2007). Characterisation and properties of Acacia senegal (L.) Willd. var, senegal with enhanced properties (Acacia (sen) SUPER GUMTM): Part 3 Immunological characterisation of Acacia (sen) SUPER GUM ${ }^{\mathrm{TM}}$. Food Hydrocolloids, 21(3), 338-346.

Randall, R. C., Phillips, G. O., \& Williams, P. A. (1988). The role of the proteinaceous component on the emulsifying properties of gum arabic. Food Hydrocolloids, 2(2), 131-140.

Randall, R. C., Phillips, G. O., \& Williams, P. A. (1989). Fractionation and characterization of gum from Acacia senegal. Food Hydrocolloids, 3(1), 65-75.

Tipvarakarnkoon, T., Einhornstoll, U., \& Senge, B. (2010). Effect of modified Acacia gum (SUPER GUM $^{\mathrm{TM}}$ ) on the stabilization of coconut o/w emulsions. Food Hydrocolloids, 24(6), 595-601.

Verbeken, D., Dierckx, S., \& Dewettinck, K. (2003). Exudate gums: occurrence, production, and 
applications. Applied Microbiology and Biotechnology, 63(1), 10-21.

Walstra, P. (1993). Principles of emulsion formation. Chemical Engineering Science, 48(2), 333-349.

Wójcik, W., Jańczuk, B., \& Białopiotrowicz, T. (1989). Correlation between floatation activity of coal, the contact angle and stability of the coal/ n -alkane film-air bubble-water system. Chemical Engineering Journal, 42(1), 63-67.

Xiang, S., Yao, X., Zhang, W., Zhang, K., Fang, Y., Nishinari, K., Phillips, G. O., \& Jiang, F. (2015). Gum Arabic-stabilized conjugated linoleic acid emulsions: Emulsion properties in relation to interfacial adsorption behaviors. Food Hydrocolloids, 48, 110-116. 